\title{
Maternal Anxiety and Infants Birthweight and Length of Gestation. A sibling design
}

Mona Bekkhus ${ }^{1 *}$, Yunsung Lee ${ }^{2,3}$, Ragnhild Eek Brandlistuen ${ }^{4}$, Sven Ove Samuelsen ${ }^{3,5}$ and Per Magnus ${ }^{2}$

\begin{abstract}
Background: The overall aim of this study is to examine the effect of prenatal maternal anxiety on birthweight and gestational age, controlling for shared family confounding using a sibling comparison design.

Methods: The data on 77,970 mothers and their 91,165 children from the population-based Mother, Father and Child Cohort Study and data on 12,480 pairs of siblings were used in this study. The mothers filled out questionnaires for each unique pregnancy, at $17^{\text {th }}$ and $30^{\text {th }}$ week in pregnancy. Gestational age and birth weight was extracted from the Medical Birth Registry of Norway (MBRN). Associations between prenatal maternal anxiety (measured across the $17^{\text {th }}$ and $30^{\text {th }}$ weeks) and birth outcomes (birthweight and gestational age) were examined using linear regression with adjustment for shared-family confounding in a sibling comparison design.
\end{abstract}

Results: In the population level analysis the maternal anxiety score during pregnancy was inversely associated with new-born's birthweight (Beta $=-63.895 \% \mathrm{Cl}$ : -92.6, -35.0) and gestational age (Beta $=-1.52,95 \% \mathrm{Cl}:-2.15,-0.89$ ) after adjustment for several covariates. The association of the maternal anxiety score with birthweight was no longer significant, but remained for maternal anxiety at $30^{\text {th }}$ week with gestational age (Beta $\left.=-1.11,95 \% \mathrm{Cl}:-1.82,-0.4\right)$ after further adjusting for the shared-family confounding in the sibling comparison design.

Conclusion: No association was found for maternal prenatal anxiety with birth weight after multiple covariates and family environment were controlled. However, there was an association between prenatal maternal anxiety at $30^{\text {th }}$ week only with gestational age, suggesting a timing effect for maternal anxiety in third trimester.

Keywords: Birthweight, Gestational age, Prenatal maternal anxiety, Sibling study

\section{Introduction}

Preterm birth (PTB) and low birthweight (LBW) are related to perinatal mortality, and have been associated with a wide range of adverse developmental outcomes for children [1]. Recently, much focus has been on the potential impact of maternal distress and anxiety, such as feeling fearful or nervous on birth outcomes. Studies have reported that the prevalence of maternal anxiety during pregnancy varies from 6.6 to $10.4 \%[2,3]$. Further, maternal anxiety during pregnancy is associated with

*Correspondence: Mona.bekkhus@psykologi.uio.no

1 Promenta Research Centre, Department of Psychology, University

of Oslo, PB 1094 Blindern, 0317 Oslo, Norway

Full list of author information is available at the end of the article birthweight and gestational age $[4,5]$. Prenatal anxiety is recognized as a potential risk factor for PTB and LBW [6-8].

While associations between prenatal maternal anxiety and PTB and LBW have been reported, causal inferences are only tentative. Addressing residual confounding by randomizing pregnant mothers to the exposure is clearly not possible [9]. Thus, in humans, investigations are limited to observational designs, and new approaches are needed to advance the field by adequately controlling for genetic and social confounding $[9,10]$.

In this study, we estimate the effects of degree (no symptoms, light symptoms and severe symptoms) and timing of prenatal maternal anxiety on infant birthweight and preterm birth. Timing was accounted for by 
examining whether symptoms were reported at either or both of the $17^{\text {th }}$ or $30^{\text {th }}$ gestational weeks. We test these associations using a sibling comparison design. The design, which involves studying birth outcomes following differential exposure to anxiety during pregnancy across siblings, has been found to reduce the extent of the impact of family-level confounding factors [9-11], on examinations of prenatal anxiety effects.

\section{Methods}

In The Norwegian Mother, Father and Child Cohort study (MoBa) [12], participants were recruited from all over Norway from 1999-2008, when attending routine ultrasound -examinations. The women consented to participation in $41 \%$ of the pregnancies, and 78,117 mothers of 91,378 children completed questionnaires at the $17^{\text {th }}$ and $30^{\text {th }}$ week of gestation of each unique pregnancy (Fig. 1). Women were included if they responded to these questionnaires, and had available data in the Medical Birth Registry of Norway (MBRN).

The questionnaires asked the mothers to report their anxiety level, in addition to providing information regarding their age, education, marital status, smoking and drinking habits, and their relationship with their partner. The MoBa cohort [12] was also linked to the MBRN, which contains detailed medical information about new-born children (gender, birthweight, and gestational age) as well as their mothers (parity and birth complications).

Among these full data sets, there were 12,480 pairs of siblings. The mean age difference between siblings was 2.77 years. The numbers of pairs dropped slightly after excluding half-siblings who had the same mother but different fathers (Fig. 1). We used version eight of the quality-assured data files. The establishment of MoBa and initial data collection was based on a license from the Norwegian Data Protection Agency and approval from The Regional Committees for Medical and Health Research Ethics (REK- 2009/1899-7). The MoBa cohort is now based on regulations related to the Norwegian Health Registry Act. The current study was approved by The Regional Committees for Medical and Health Research Ethics (REK 2016/1424).

\section{Measures}

\section{Measures of maternal general anxiety}

Mothers reported symptoms of anxiety using validated short versions of two Hopkins Symptom Checklists, the SCL-5 (at $17^{\text {th }}$ week of gestation) and SCL-8 (at $30^{\text {th }}$ week of gestation). Participants answered to the question 'Have you been bothered by any of the following during the last two weeks'. Items, reflecting e.g. feeling fearful, nervousness or shakiness inside were scored on a Likert scale ranging from 1 (not at all bothered) to 4 (very much bothered) and have been validated at a correlation of 0.92 with the SCL-25 [13]. Assessments of anxiety were reported in the $17^{\text {th }}$ week by two items from SCL-5, and four questions from SCL-8 in the $30^{\text {th }}$ week of each pregnancy. The mean score for the $17^{\text {th }}$ and $30^{\text {th }}$ gestational week measure ranged from 1-4. The "week 17" in Tables 3 and 4 represents the effect of maternal anxiety score at $17^{\text {th }}$ gestational week on the birth outcomes (birthweight and gestational age), and so does the "week 30 " that of maternal anxiety score at $30^{\text {th }}$ week on the birth outcomes. The "Both" represents the additive effect of maternal anxiety score at $17^{\text {th }}, 30^{\text {th }}$ gestational week and the interaction.

The mean score for the two assessments ranged from 1.2 to 1.4 and included the following items: constantly frightened or anxious; nervous, inner turmoil; tense or stressed; and sudden fear without reason.

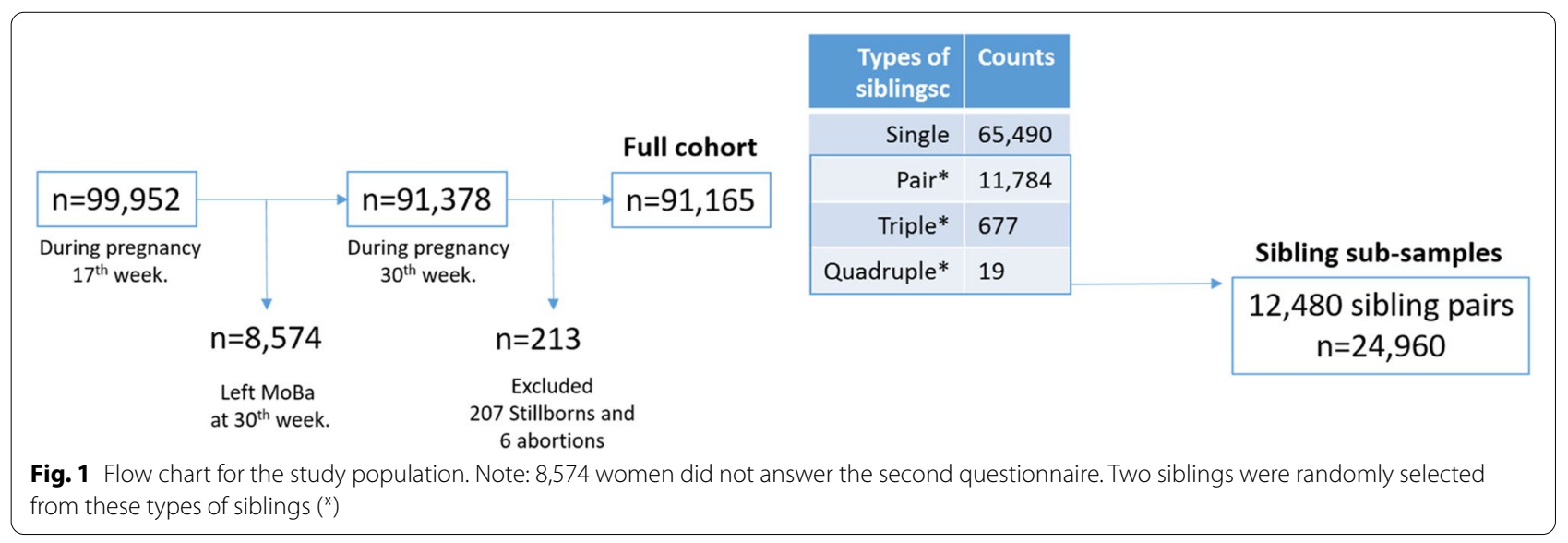




\section{Birthweight and Gestational age}

Birthweight (measured in grams) was extracted from the Medical Birth Registry of Norway (MBRN) and was treated as a continuous scale producing a mean value of 3,608 (SD 544.8). Gestational age (measured in days) was also treated as a continuous variable and the mean score was 39.5 (SD 1.72). All maternity units in Norway must notify the MBRN of all births and pregnancies terminating after week 12. The MBRN includes information on pre- and post-pregnancy variables including medication, birth complication, and maternal complications.

\section{Assessment of potential confounders}

Potential confounding factors were considered based on whether they could influence both prenatal maternal anxiety and child development outcomes, and were included in the adjusted model if associated with the exposure (prenatal maternal anxiety) and one of the two outcome measures. The following variables were considered to be potential confounders: alcohol consumption during pregnancy (coded as ' 0 ' for never and ' 1 ' for more than once a month); smoking in pregnancy (coded as ' 0 ' for never, ' 1 ' for sometimes, and ' 2 ' for daily); marital status (coded as ' 0 ' for married/living together and ' 1 ' for single); and maternal education coded as ' 0 ' for higher university degree $(+4$ years college/university), and ' 1 ' ( 3 years college/university), ' 2 ' for 1-2 years college, and ' 3 ' for secondary school). The following variables extracted from the MBRN were also controlled for: maternal age as a continuous variable; parity coded as itself, where greater than or equal to 4 was coded as $4+$; birth complications (coded as ' 1 ' for yes or ' 0 ' for no); child's sex (coded as ' 0 ' for girl and ' 1 ' for boy); and preeclampsia (coded as ' 0 ' for no and ' 1 ' for yes).

\section{Statistical analyses}

Multiple regressions were used to estimate the effects of prenatal maternal anxiety on birthweight and gestational age. In a full cohort where all subjects with the exposures, outcomes and adjusting variables were included, we regressed birthweight and gestational age on maternal anxiety score at $17^{\text {th }}$ and $30^{\text {th }}$ gestational week, their interactions (Crude in Table 3 and 4), and further included adjusting variables step by step. Step1 encompassed maternal smoking and alcohol intake, and step 2 included in addition parity, birth complication, child's sex and preeclampsia. Step 3 added maternal age, education and marital status. Regression analyses were performed in $\mathrm{R}$ 4.0.0.

In the sibling comparison design, we selected all available sibling pairs (for families participating with three or more children, one sibling pair was randomly selected) and computed the difference values in each variable between a sibling and the other. Similar to the analyses in the full cohort, we regressed the sibling-difference values in the outcomes on those in the exposures, controlling for family shared effects. Here, the three steps of adjustments were made in the same manner as in the full cohort.

We performed multiple imputations to handle the missing data points in the exposures, outcomes and adjusting variables. The mice $\mathrm{R}$ package was used; the number of imputations was set to be $5(\mathrm{~m}=5)$, and the imputation method in use was predictive mean matching (method="pmm").

\section{Results}

In the full cohort (Table 1), the mean birthweight of infants of mothers reporting severe anxiety symptoms in the $17^{\text {th }}$ gestational week was 85 grams lower than that of infants born to mothers with very light anxiety symptoms or none at all $(p<0.001)$. Similarly, the mean birthweight of infants born to mothers reporting severe anxiety symptoms in the $30^{\text {th }}$ gestational week was 95 grams lower than that of infants not exposed to high levels of maternal anxiety $(\mathrm{p}<0.001)$. The mean gestational age between light and severe maternal anxiety differed by 2.2 days for those reporting maternal anxiety in the $17^{\text {th }}$ gestational week $(p<0.001)$. Between light and severe anxiety symptoms reported in the $30^{\text {th }}$ gestational week, the mean gestational age decreased by 3.4 days $(p<0.001)$.

Among the 24,960 siblings (see Table 2), a mean birthweight difference between infants born to mothers reporting light anxiety symptoms and those born to mothers reporting severe anxiety symptoms was also found. However, for the sibling subsample, only a 44 gram difference in mean birthweight was recorded for infants exposed to light anxiety or none at all, as reported in the $17^{\text {th }}$ gestational week $(\mathrm{p}<0.01)$. Mean birthweight for infants exposed to severe compared to light or no maternal anxiety, as reported in the $30^{\text {th }}$ gestational week, differed by 153 grams ( $<<0.01)$. Mean gestational age decreased by 1.4 days between infants born to mothers reporting severe symptoms and infants born to mothers reporting light symptoms in the $17^{\text {th }}$ gestational week $(\mathrm{p}<0.05)$; however, this difference was 3.5 days for those reporting symptoms in the $30^{\text {th }}$ gestational week $(\mathrm{p}<0.001)$.

The differences in maternal anxiety levels between two pregnancies were also examined. Of the mothers who participated MoBa twice, 4,015 mothers (32\%) experienced more anxiety during their first pregnancy than during their second pregnancy, while 2,252 mothers (18\%) had the opposite experience. The rest of the mothers $(50 \%)$ experienced the same anxiety levels during 
Table 1 Characteristics of full cohort

\begin{tabular}{|c|c|c|c|c|c|}
\hline & \multirow{3}{*}{$\begin{array}{l}\text { Count } \\
\mathrm{n}=91,165\end{array}$} & \multicolumn{2}{|c|}{ Birthweight (in grams) } & \multicolumn{2}{|c|}{ Gestational age (in days) } \\
\hline & & \multirow{2}{*}{$\begin{array}{l}\text { Mean } \\
\mu=3,610.3\end{array}$} & \multirow{2}{*}{$\begin{array}{l}\text { SD } \\
\mathrm{s}=542.3\end{array}$} & \multirow{2}{*}{$\begin{array}{l}\text { Mean } \\
\mu=279.7\end{array}$} & \multirow{2}{*}{$\begin{array}{l}\text { SD } \\
s=11.7\end{array}$} \\
\hline & & & & & \\
\hline \multicolumn{6}{|c|}{ Maternal anxiety at week 17 (score) } \\
\hline 1-2, Light & 80,233 & $3,615.1$ & 540.2 & 279.8 & 11.7 \\
\hline $2-3$ & 8,022 & $3,581.1$ & 554.3 & 279.1 & 12.1 \\
\hline 3-4, Severe & 1,362 & $3,529.9$ & 573.0 & 277.6 & 12.9 \\
\hline NA & 1,548 & $3,583.5$ & 545.7 & 279.0 & 12.0 \\
\hline \multicolumn{6}{|c|}{ Maternal anxiety at week 30 (score) } \\
\hline 1-2, Light & 85,064 & $3,615.0$ & 537.3 & 279.9 & 11.5 \\
\hline $2-3$ & 4,690 & $3,559.4$ & 572.9 & 278.5 & 13.2 \\
\hline 3-4, Severe & 639 & $3,519.8$ & 643.1 & 276.5 & 15.6 \\
\hline NA & 772 & $3,470.6$ & 728.9 & 275.5 & 20.1 \\
\hline \multicolumn{6}{|l|}{ Maternal age } \\
\hline$<25$ & 9,862 & $3,552.4$ & 547.6 & 279.0 & 12.3 \\
\hline $25-29$ & 30,223 & $3,592.8$ & 533.2 & 279.7 & 11.6 \\
\hline $30-34$ & 35,280 & $3,631.6$ & 536.4 & 279.9 & 11.4 \\
\hline$>=35$ & 15,800 & $3,632.0$ & 564.9 & 279.6 & 12.2 \\
\hline \multicolumn{6}{|l|}{ Partner harmony (score) } \\
\hline $1-2$, Good & 64,618 & $3,602.6$ & 540.2 & 279.8 & 11.8 \\
\hline $2-3$ & 19,726 & $3,638.9$ & 538.4 & 279.8 & 11.4 \\
\hline $3-4$ & 3,977 & $3,646.6$ & 537.8 & 279.6 & 11.2 \\
\hline $4-5$ & 919 & $3,637.1$ & 581.1 & 278.8 & 12.1 \\
\hline 5-6, Bad & 359 & $3,518.4$ & 570.4 & 278.8 & 11.5 \\
\hline NA & 1,566 & $3,476.8$ & 617.3 & 278.0 & 14.8 \\
\hline \multicolumn{6}{|l|}{ Education } \\
\hline University 4y+ & 20,406 & $3,602.9$ & 525.4 & 280.3 & 11.3 \\
\hline College/University 3y & 35,732 & $3,620.1$ & 534.3 & 279.8 & 11.6 \\
\hline College 1-2y & 12,684 & $3,623.4$ & 555.7 & 279.7 & 12.0 \\
\hline Secondary school & 17,720 & $3,595.2$ & 566.3 & 278.8 & 12.3 \\
\hline NA & 4,623 & $3,588.3$ & 542.6 & 279.8 & 12.0 \\
\hline \multicolumn{6}{|l|}{ Marital status } \\
\hline Married/Partner & 87,656 & $3,613.7$ & 540.9 & 279.7 & 11.7 \\
\hline Single & 3,509 & $3,523.1$ & 568.3 & 279.1 & 12.3 \\
\hline \multicolumn{6}{|l|}{ Parity } \\
\hline 0 & 41,316 & $3,505.5$ & 535.4 & 279.9 & 12.5 \\
\hline 1 & 32,276 & $3,683.5$ & 523.1 & 279.8 & 10.8 \\
\hline 2 & 13,754 & $3,725.8$ & 541.4 & 279.4 & 11.1 \\
\hline 3 & 2,912 & $3,723.1$ & 562.3 & 278.7 & 11.8 \\
\hline 4 & 907 & $3,661.1$ & 601.8 & 276.5 & 13.1 \\
\hline \multicolumn{6}{|c|}{ Alcohol consumption during pregnancy } \\
\hline Never & 74,786 & $3,611.1$ & 541.7 & 279.7 & 11.8 \\
\hline $1+/$ month & 533 & $3,567.4$ & 537.9 & 280.4 & 12.1 \\
\hline NA & 15,846 & $3,607.6$ & 545.1 & 279.8 & 11.7 \\
\hline \multicolumn{6}{|l|}{ Smoking during pregnancy } \\
\hline None & 81,879 & $3,621.6$ & 538.9 & 279.8 & 11.6 \\
\hline Sometimes & 4,018 & $3,570.9$ & 554.5 & 279.9 & 12.3 \\
\hline Daily & 3,746 & $3,420.1$ & 553.4 & 278.5 & 12.4 \\
\hline NA & 1,522 & $3,571.3$ & 566.9 & 279.2 & 13.2 \\
\hline
\end{tabular}


Table 1 (continued)

\begin{tabular}{|c|c|c|c|c|c|}
\hline & \multirow{3}{*}{$\begin{array}{l}\text { Count } \\
n=91,165\end{array}$} & \multicolumn{2}{|c|}{ Birthweight (in grams) } & \multicolumn{2}{|c|}{ Gestational age (in days) } \\
\hline & & \multirow{2}{*}{$\begin{array}{l}\text { Mean } \\
\mu=3,610.3\end{array}$} & \multirow{2}{*}{$\begin{array}{l}\text { SD } \\
s=542.3\end{array}$} & \multirow{2}{*}{$\begin{array}{l}\text { Mean } \\
\mu=279.7\end{array}$} & \multirow{2}{*}{$\begin{array}{l}S D \\
s=11.7\end{array}$} \\
\hline & & & & & \\
\hline \multicolumn{6}{|c|}{ Birth complication } \\
\hline No & 66,220 & $3,627.8$ & 546.0 & 280.1 & 11.9 \\
\hline Yes & 24,945 & $3,563.6$ & 529.3 & 278.6 & 11.3 \\
\hline \multicolumn{6}{|c|}{ Child sex } \\
\hline Girl & 44,450 & $3,546.2$ & 524.6 & 279.2 & 11.5 \\
\hline Boy & 46,715 & $3,671.2$ & 551.7 & 280.2 & 12.0 \\
\hline NA & 87,792 & $3,624.7$ & 524.6 & 280.1 & 11.2 \\
\hline \multicolumn{6}{|c|}{ Preeclampsia } \\
\hline Yes & 3,373 & $3,234.0$ & 799.2 & 270.2 & 19.2 \\
\hline No & 80,233 & $3,615.1$ & 540.2 & 279.8 & 11.7 \\
\hline
\end{tabular}

their first and second pregnancies. The mean difference between maternal anxiety during first and second pregnancies was small $\left(\right.$ mean $\left._{\text {diff }}=0.05\right)$.

\section{Regression analyses for prenatal maternal anxiety and birthweight}

First, as shown in Table 3 (and Fig. 2), the maternal anxiety score at the $17^{\text {th }}$ week was associated with birthweight. A stronger association was found for those reporting symptoms in the $30^{\text {th }}$ week. Children exposed to maternal anxiety prenatally, as reported at both the $17^{\text {th }}$ and $30^{\text {th }}$ gestational weeks, were at higher risk of low birthweight compared to those not exposed and those exposed only once during pregnancy. This association was reduced, but remained, after adjusting for smoking and alcohol consumption. In addition, adjustments for potential confounders at steps 2 and 3 found the association to be weaker but still significant.

Sibling-comparison analyses found maternal anxiety to be associated with low birthweight when reported in only the $17^{\text {th }}$ gestational week and in only the $30^{\text {th }}$ gestational week. Children exposed to maternal anxiety as reported in both the $17^{\text {th }}$ and $30^{\text {th }}$ gestational weeks were at the highest risk of low birthweight, even after sharedfamily confounding was adjusted for. This association remained robust after adjusting for smoking and alcohol intake during pregnancy. However, the association was no longer significant when the birth-related and sociodemographic variables were controlled for.

\section{Regression analyses for prenatal maternal anxiety and gestational age}

We also examined the association between maternal anxiety and gestation (Table 4 and Fig. 3). In the full cohort, a stronger association was found for those reporting symptoms in the $30^{\text {th }}$ week. Children exposed to maternal anxiety prenatally, across both the $17^{\text {th }}$ and $30^{\text {th }}$ gestational weeks, were at higher risk of short gestational age, compared to those not exposed and those exposed only once during pregnancy. This association was only moderately reduced, after adjusting for smoking and alcohol consumption and remained significant. Similarly to the associations for birthweight, these associations was further reduced, but remained robust after adjusting for multiple birth-related and socio-demographic variables in step 2 and 3.

In the sibling-design, we found no significant associations between maternal anxiety at $17^{\text {th }}$ week only and gestational age. The association between prenatal maternal anxiety at week 30 and gestational age remained in the sibling cohort, adjusting for shared family effects and control variables in all steps.

\section{Discussion}

This study aimed to examine the effect of both the degree and timing of prenatal maternal anxiety on infant birthweight and gestational age. Therefore, the association between no symptoms, light symptoms and severe symptoms of anxiety with adverse birth outcome and gestation was examined. Timing was also accounted for by examining whether symptoms were reported at either or both of the $17^{\text {th }}$ or $30^{\text {th }}$ gestational weeks. The second aim was to test these associations using a sibling comparison design.

\section{Main finding and interpretation}

Infants of mothers reporting severe anxiety symptoms in the $17^{\text {th }}$ and 30th gestational week were more likely to have lower birth weight than infants born to mothers with very light anxiety symptoms or none at all. This association was reduced, but remained, after adjusting 
Table 2 Characteristics of sibling sub-sample

\begin{tabular}{|c|c|c|c|c|c|}
\hline & \multirow{3}{*}{$\begin{array}{l}\text { Count } \\
\mathrm{n}=24,960\end{array}$} & \multicolumn{2}{|c|}{ Birthweight (in grams) } & \multicolumn{2}{|c|}{ Gestational age (in days) } \\
\hline & & \multirow{2}{*}{$\begin{array}{l}\text { Mean } \\
\mu=3,639.5\end{array}$} & \multirow{2}{*}{$\begin{array}{l}S D \\
s=523.0\end{array}$} & \multirow{2}{*}{$\begin{array}{l}\text { Mean } \\
\mu=280.0\end{array}$} & \multirow{2}{*}{$\begin{array}{l}\text { SD } \\
s=11.3\end{array}$} \\
\hline & & & & & \\
\hline \multicolumn{6}{|c|}{ Maternal anxiety at week 17 (score) } \\
\hline 1-2, Light & 22,888 & $3,642.9$ & 521.4 & 280.1 & 11.2 \\
\hline $2-3$ & 1,571 & $3,602.7$ & 538.5 & 279.5 & 11.8 \\
\hline 3-4, Severe & 219 & $3,598.8$ & 510.1 & 278.7 & 11.0 \\
\hline NA & 282 & $3,596.6$ & 563.2 & 279.1 & 12.0 \\
\hline \multicolumn{6}{|c|}{ Maternal anxiety at week 30 (score) } \\
\hline 1-2, Light & 23,836 & $3,642.5$ & 519.2 & 280.1 & 11.1 \\
\hline $2-3$ & 890 & $3,605.8$ & 562.6 & 279.3 & 12.8 \\
\hline 3-4, Severe & 104 & $3,489.5$ & 575.4 & 276.6 & 14.6 \\
\hline NA & 130 & $3,444.3$ & 767.5 & 274.0 & 22.3 \\
\hline \multicolumn{6}{|l|}{ Maternal age } \\
\hline$<25$ & 2,306 & $3,598.8$ & 540.8 & 279.1 & 12.0 \\
\hline $25-29$ & 8,883 & $3,623.9$ & 521.0 & 280.0 & 11.3 \\
\hline $30-34$ & 10,265 & $3,655.6$ & 517.1 & 280.2 & 11.0 \\
\hline$>=35$ & 3,506 & $3,658.4$ & 530.4 & 280.1 & 11.4 \\
\hline \multicolumn{6}{|l|}{ Partner harmony (score) } \\
\hline $1-2$, Good & 18,030 & $3,628.7$ & 522.6 & 280.0 & 11.3 \\
\hline $2-3$ & 5,497 & $3,669.9$ & 516.2 & 280.3 & 10.9 \\
\hline $3-4$ & 984 & $3,686.4$ & 518.7 & 280.1 & 10.5 \\
\hline $4-5$ & 198 & $3,698.8$ & 549.8 & 278.6 & 13.0 \\
\hline 5-6, Bad & 47 & $3,577.9$ & 470.7 & 280.7 & 9.4 \\
\hline NA & 204 & $3,501.4$ & 660.7 & 276.8 & 16.8 \\
\hline \multicolumn{6}{|l|}{ Education } \\
\hline University 4y+ & 6,432 & $3,634.1$ & 507.0 & 280.5 & 10.9 \\
\hline College/University 3y & 10,958 & $3,641.6$ & 523.6 & 280.0 & 11.2 \\
\hline College 1-2y & 2,945 & $3,647.4$ & 528.8 & 279.8 & 11.7 \\
\hline Secondary school & 3,572 & $3,635.8$ & 541.7 & 279.3 & 11.6 \\
\hline NA & 1,053 & $3,640.2$ & 531.7 & 280.5 & 11.4 \\
\hline \multicolumn{6}{|l|}{ Marital status } \\
\hline Married/Partner & 24,420 & $3,640.4$ & 522.3 & 280.0 & 11.3 \\
\hline Single & 540 & $3,596.7$ & 548.9 & 278.9 & 11.4 \\
\hline \multicolumn{6}{|l|}{ Parity } \\
\hline 0 & 9,425 & $3,535.0$ & 528.3 & 280.1 & 12.4 \\
\hline 1 & 11,388 & $3,692.1$ & 505.2 & 280.1 & 10.3 \\
\hline 2 & 3,279 & $3,739.1$ & 513.3 & 279.8 & 10.5 \\
\hline 3 & 654 & $3,736.3$ & 514.2 & 279.5 & 11.2 \\
\hline 4 & 214 & $3,619.2$ & 616.9 & 276.6 & 13.5 \\
\hline \multicolumn{6}{|c|}{ Alcohol consumption during pregnancy } \\
\hline Never & 21,072 & $3,641.0$ & 521.0 & 280.0 & 11.2 \\
\hline $1+/$ month & 97 & $3,602.8$ & 559.2 & 281.5 & 13.5 \\
\hline NA & 3,791 & $3,632.0$ & 532.8 & 280.0 & 11.5 \\
\hline \multicolumn{6}{|l|}{ Smoking during pregnancy } \\
\hline None & 23,251 & $3,646.5$ & 521.3 & 280.0 & 11.2 \\
\hline Sometimes & 743 & $3,577.1$ & 533.9 & 280.4 & 11.7 \\
\hline Daily & 589 & $3,442.7$ & 528.1 & 278.6 & 12.0 \\
\hline NA & 377 & $3,637.3$ & 529.2 & 279.9 & 13.0 \\
\hline
\end{tabular}


Table 2 (continued)

\begin{tabular}{|c|c|c|c|c|c|}
\hline & \multirow[t]{2}{*}{ Count } & \multicolumn{2}{|c|}{ Birthweight (in grams) } & \multicolumn{2}{|c|}{ Gestational age (in days) } \\
\hline & & Mean & SD & Mean & SD \\
\hline & $n=24,960$ & $\mu=3,639.5$ & $s=523.0$ & $\mu=280.0$ & $s=11.3$ \\
\hline \multicolumn{6}{|c|}{ Birth complication } \\
\hline No & 17,519 & $3,662.7$ & 528.6 & 280.5 & 11.5 \\
\hline Yes & 7,441 & $3,584.8$ & 505.3 & 279.0 & 10.7 \\
\hline \multicolumn{6}{|c|}{ Child sex } \\
\hline Girl & 12,172 & $3,579.4$ & 504.2 & 279.5 & 10.9 \\
\hline Boy & 12,788 & $3,696.7$ & 534.0 & 280.5 & 11.6 \\
\hline NA & 24,164 & $3,650.9$ & 507.5 & 280.3 & 10.8 \\
\hline \multicolumn{6}{|c|}{ Preeclampsia } \\
\hline Yes & 796 & $3,292.1$ & 796.2 & 270.8 & 18.8 \\
\hline No & 22,888 & $3,642.9$ & 521.4 & 280.1 & 11.2 \\
\hline
\end{tabular}

Table 3 Effect of maternal anxiety on birth weight

\begin{tabular}{|c|c|c|c|c|}
\hline & $\begin{array}{l}\text { Crude } \\
\text { Beta }[95 \% \mathrm{Cl}]\end{array}$ & $\begin{array}{l}\text { Step } 1^{*} \\
\text { Beta }[95 \% \mathrm{Cl}]\end{array}$ & $\begin{array}{l}\text { Step2 }{ }^{* *} \\
\text { Beta }[95 \% \mathrm{Cl}]\end{array}$ & $\begin{array}{l}\text { Step3 } 3^{* * *} \\
\text { Beta }[95 \% \mathrm{Cl}]\end{array}$ \\
\hline \multicolumn{5}{|l|}{ Full cohort } \\
\hline No Anxiety & 0 [Reference] & 0 [Reference] & 0 [Reference] & 0 [Reference] \\
\hline Week 17 & $-56.5[-78.8,-34.2]$ & $-48.9[-71.2,-26.6]$ & $-22[-43.7,-0.4]$ & $-25.4[-47.1,-3.8]$ \\
\hline Week 30 & $-83.1[-106.7,-59.5]$ & $-71.4[-94.9,-47.8]$ & $-44[-66.7,-21.2]$ & $-47.8[-70.6,-25.1]$ \\
\hline Both & $-116.6[-146.3,-86.9]$ & $-99.2[-128.8,-69.5]$ & $-58[-86.8,-29.2]$ & $-63.8[-92.6,-35]$ \\
\hline Sample size & 91,165 & 91,165 & 91,165 & 91,165 \\
\hline \multicolumn{5}{|l|}{ Sibling cohort } \\
\hline No Anxiety & 0 [Reference] & 0 [Reference] & 0 [Reference] & 0 [Reference] \\
\hline Week 17 & $-34.8[-58.9,-10.7]$ & $-33.2[-57.3,-9.1]$ & $-4.5[-27.4,18.5]$ & $-4.7[-27.6,18.3]$ \\
\hline Week 30 & $-57.5[-88,-27]$ & $-56.9[-87.5,-26.3]$ & $-27.7[-56.9,1.5]$ & $-27.9[-57.2,1.3]$ \\
\hline Both & $-139[-184.5,-93.4]$ & $-134.8[-180.4,-89.2]$ & $-33.5[-77.8,10.8]$ & $-33.1[-77.4,11.2]$ \\
\hline Sample size ${ }^{1}$ & 12,480 & 12,480 & 12,480 & 12,480 \\
\hline
\end{tabular}

*Adjusted for smoking and alcohol intake.

**Adjusted for smoking, alcohol intake, parity, birth complication, child's sex and preeclampsia.

*** Adjusted for smoking, alcohol intake, parity, birth complication, child's sex, preeclampsia, maternal age, education and marital status.

${ }^{1}$ Number of sibling "pairs".

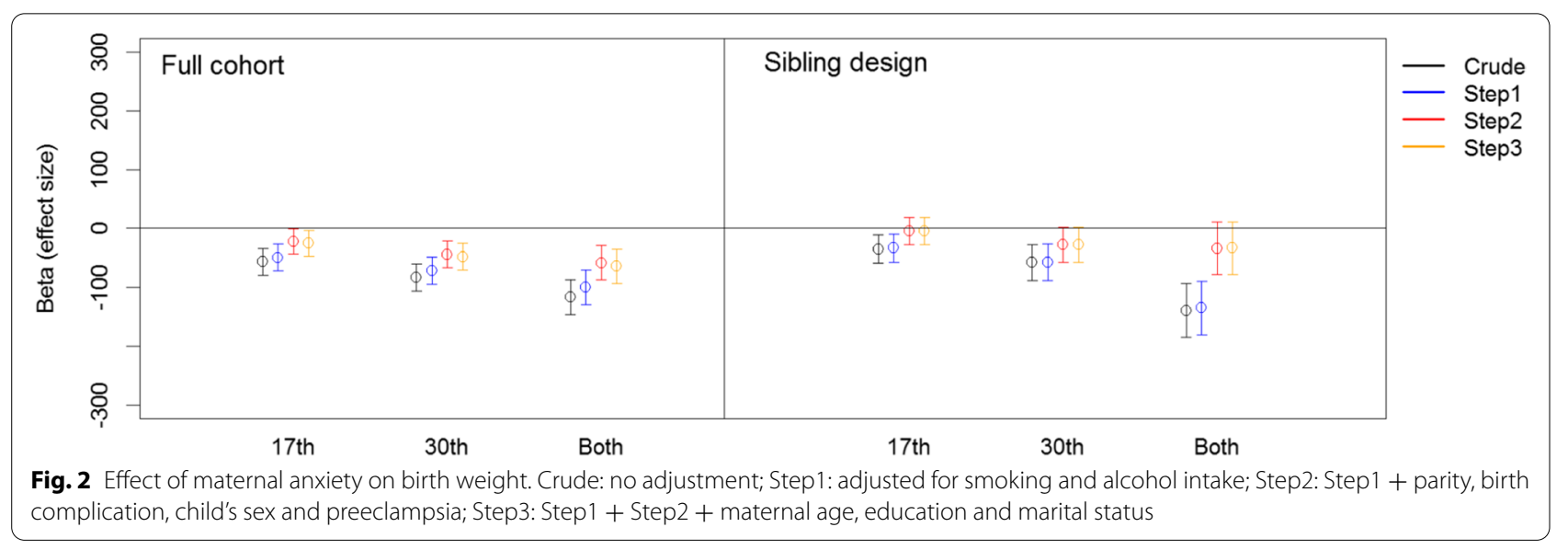


Table 4 Effect of maternal anxiety on gestational age

\begin{tabular}{|c|c|c|c|c|}
\hline & $\begin{array}{l}\text { Crude } \\
\text { Beta }[95 \% \mathrm{Cl}]\end{array}$ & $\begin{array}{l}\text { Step } 1^{*} \\
\text { Beta }[95 \% \mathrm{Cl}]\end{array}$ & $\begin{array}{l}\text { Step2 }{ }^{* *} \\
\text { Beta }[95 \% \mathrm{Cl}]\end{array}$ & $\begin{array}{l}\text { Step3 } 3^{* * *} \\
\text { Beta }[95 \% \mathrm{CI}]\end{array}$ \\
\hline \multicolumn{5}{|l|}{ Full cohort } \\
\hline No Anxiety & 0 [Reference] & 0 [Reference] & 0 [Reference] & 0 [Reference] \\
\hline Week 17 & $-0.64[-1.12,-0.16]$ & $-0.61[-1.09,-0.13]$ & $-0.54[-1.01,-0.07]$ & $-0.44[-0.91,0.04]$ \\
\hline Week 30 & $-1.4[-1.9,-0.89]$ & $-1.35[-1.86,-0.84]$ & $-1.23[-1.73,-0.74]$ & $-1.14[-1.64,-0.64]$ \\
\hline Both & $-1.89[-2.53,-1.25]$ & $-1.82[-2.46,-1.18]$ & $-1.69[-2.32,-1.06]$ & $-1.52[-2.15,-0.89]$ \\
\hline Sample size & 91,165 & 91,165 & 91,165 & 91,165 \\
\hline \multicolumn{5}{|l|}{ Sibling cohort } \\
\hline No Anxiety & 0 [Reference] & 0 [Reference] & 0 [Reference] & 0 [Reference] \\
\hline Week 17 & $0.35[-0.21,0.92]$ & $0.35[-0.21,0.92]$ & $0.37[-0.19,0.94]$ & $0.36[-0.2,0.93]$ \\
\hline Week 30 & $-1.08[-1.79,-0.37]$ & $-1.08[-1.8,-0.37]$ & $-1.13[-1.84,-0.42]$ & $-1.11[-1.82,-0.4]$ \\
\hline Both & $-0.54[-1.61,0.52]$ & $-0.54[-1.61,0.53]$ & $-0.6[-1.68,0.47]$ & $-0.54[-1.62,0.53]$ \\
\hline Sample size ${ }^{1}$ & 12,480 & 12,480 & 12,480 & 12,480 \\
\hline
\end{tabular}

* Adjusted for smoking and alcohol intake.

** Adjusted for smoking, alcohol intake, parity, birth complication, child's sex and preeclampsia.

${ }^{* * *}$ Adjusted for smoking, alcohol intake, parity, birth complication, child's sex, preeclampsia, maternal age, education and marital status.

${ }^{1}$ Number of sibling "pairs".

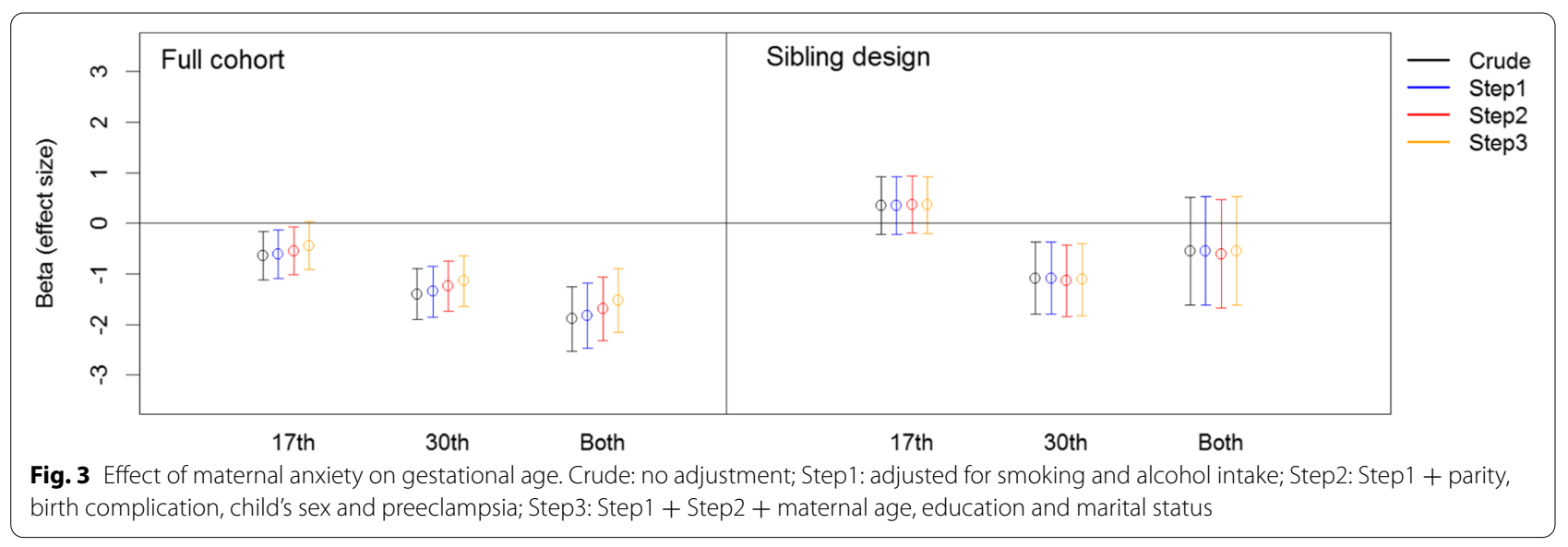

for several controls in the full sample. However, in the sibling subsample, once multiple covariates were controlled for, the association was no longer significant. In regard to prenatal anxiety and gestational age, there was no significant change before and after family adjustment. However in the sibling analyses, only maternal anxiety at week 30 in pregnancy was significantly associated with shorter gestational age.

Mean birthweight was lower for infants born to mothers reporting severe symptoms of anxiety, and the lowest birthweight was found for exposure to anxiety symptoms as reported in the $30^{\text {th }}$ gestational week. These findings are also in accordance with a meta-analysis performed by Ding et al. [5], which found that maternal anxiety was associated with an increased probability of low birthweight. However, after we adjusted for shared family factors and multiple covariates, there were no association between maternal anxiety and birthweight. This finding suggests the importance of controlling for multiple confounding.

In regard to prenatal anxiety and gestational age, maternal anxiety at week 30 in pregnancy was significantly associated with shorter gestational age. This finding suggests a timing effect of maternal anxiety. During the third trimester in a pregnancy, the fetus grows rapidly, and these findings suggest that severe symptoms of anxiety later in pregnancy increase the chance of a short gestational age. The findings persisted also in the sibling analyses, following control for multiple covariates; such as smoking and alcohol exposure, birth complications, 
and the socio-economic status of the mother. However, we did not control previous psychiatric diagnoses or life stressors, which could be influencing maternal anxiety levels. Nevertheless, this finding is in accordance with previous studies examining prenatal anxiety and birth outcomes $[5,14,15]$.

There are several hypotheses regarding the influence of maternal anxiety on fetal growth and gestation. One such mechanism involves changes to maternal hypothalamicpictuary-adrenal (HPA) axis activity [16] That is, it is suggested that maternal anxiety during pregnancy increases the production of stress hormones such as cortisol and catecholamines [17, 18]. Animal models have found these stress hormones to influence uterine blood flow and immunologic functioning, thus potentially increasing risk of shortened gestational length and lower fetal growth [19]. Another potential explanation for this link, could be through higher risks of infections due to stress. Studies suggests that high levels of stress may be linked to lower immune function [20], and increased infections during pregnancy that could shorten gestation [21]

\section{Strengths and limitations}

There are several strengths to this study. First, the prospective nature of this study reflects the direction of effects and enhances the validity of measurements. In addition, the large sample size provided a range of opportunities to adequately control for confounding factors. This enabled examination of the association between maternal anxiety and birthweight and gestation in a stepwise manner. That is, several confounders could be included at different levels, such as those operating prenatally, as well as those related to birthweight and gestation (e.g. birth complications). Contextual factors such as maternal age and education could also be included. A potential limitation in the current paper, however, is that we were not able to control for previous psychiatric disorders, or the use of medications such as SSRIs, which could be influencing maternal anxiety levels. Next, the unique sample included a large sibling population, which allowed adequate control for family effects such as genetic confounding. This design can be helpful for ruling out measurement error due to familial factors, such as shared genetic factors [11]. Thus, a sibling comparison design using a large cohort study can test whether associations differ between children born after subsequent pregnancies to the same mother. A discordant sibling design could also rule out all environmental differences that may vary between families, which can't be done using a population comparison design [22].

However, although the sibling design can control for familial factors to a certain extent, it is still important to note that associations could still be confounded by unmeasured unshared environmental factors [23]. The women participating with multiple pregnancies might also represent a biased selection: there is a possibility that the first pregnancy influences the second, as has been suggested by Sjölander et al. [24] and Frisell et al. [25]. It should also be noted that important moderators that could influence maternal anxiety have not been examined (for example, gene-environment interactions). In addition, the self-reported maternal anxiety score might include bias because under-reporting of anxiety symptoms was often observed due to the social stigma about mental health problems, and especially a desire to appear healthy for the expected newborns.

\section{Conclusion}

The main effect of exposure to maternal anxiety on birth weight remained after adjusting for multiple confounding in the full cohort, but not after controlling for shared family confounding. However, the association between maternal anxiety in week 30 and gestational age remained after adjusting for multiple confounding and shared family effects. The implication of these findings, suggests that there is a timing effect for maternal anxiety in third trimester.

\section{Abbreviations}

PTB: Preterm birth; LBW: low birthweight; MoBa: The Mother Father and Child cohort study; MBRN: Medical Borth Registry of Norway.

\section{Acknowledgements}

The Norwegian Mother, Father and Child Cohort Study is supported by the Norwegian Ministry of Health and Care Services and the Ministry of Education and Research. We are grateful to all the participating families in Norway who take part in this on-going cohort study.

\section{Authors' contributions}

MB: Conceptualization, Writing- original draft preparation, Funding acquisition. YL:, Formal analysis, Writing- Reviewing and Editing, Visualization. REB: Writing- Reviewing and Editing. SOS: Analyses, supervision, Writing-Reviewing and Editing, PM: Conceptualization, Writing- Reviewing and Editing, Project administration, Data curation, Funding acquisition. The authors read and approved the final manuscript.

\section{Funding}

The Norwegian Mother and Child Cohort Study is supported by the Norwegian Ministry of Health, and the Norwegian Research Council/FUGE (grant no. 151918/S10). This work was partly supported by the Research Council of Norway through its Centres of Excellence funding scheme, project number 262700 and Grant Number 288083, 301004.

Availability of data and materials

The datasets used and/or analyzed during the current study are available from the corresponding author on reasonable request.

\section{Declarations}

Ethics approval and consent to participate Informed consent was obtained from all participants. All methods were carried out in accordance with relevant guidelines and regulations. The Regional Committees for Medical and Health Research Ethics (REK- 2016/1424) and the Norwegian Data Inspectorate have approved the study. 


\section{Consent for publication}

Not relevant

\section{Competing interests}

The authors declare that they have no competing interests.

\begin{abstract}
Author details
${ }^{1}$ Promenta Research Centre, Department of Psychology, University of Oslo, PB 1094 Blindern, 0317 Oslo, Norway. ${ }^{2}$ Centre for Fertility and Health, Norwegian Institute of Public Health, Oslo, Norway. ${ }^{3}$ Department of Genetics and Bioinformatics, Norwegian Institute of Public Health, Oslo, Norway. ${ }^{4}$ Department of Child Health and Development, Norwegian Institute of Public Health, Oslo, Norway. ${ }^{5}$ Department of Mathematics, University of Oslo, Oslo, Norway.
\end{abstract}

\section{Received: 8 March 2021 Accepted: 23 November 2021}

Published online: 07 December 2021

\section{References}

1. AMS. Identifying the environmental causes of disease: how should we decide what to believe and when to take action? London: Academy of Medical Sciences; 2007

2. Andersson L, Sundström-Poromaa I, Bixo M, Wulff M, Bondestam K, Åström M. Point prevalence of psychiatric disorders during the second trimester of pregnancy: a population-based study. Am J Obstet Gynecol. 2003;189(1):148-54.

3. Berle J, Mykletun A, Daltveit AK, Rasmussen S, Holsten F, Dahl AA. Neonatal outcomes in offspring of women with anxiety and depression during pregnancy. Arch Womens Ment Health. 2005;8(3):181-9.

4. Accortt EE, Cheadle AC, Schetter CD. Prenatal depression and adverse birth outcomes: an updated systematic review. Matern Child Health J. 2015;19(6):1306-37.

5. Ding X-X, Wu Y-L, Xu S-J, Zhu R-P, Jia X-M, Zhang S-F, et al. Maternal anxiety during pregnancy and adverse birth outcomes: a systematic review and meta-analysis of prospective cohort studies. J Affective Disorders. 2014;159:103-10.

6. Loomans EM, Van Dijk AE, Vrijkotte TG, Van Eijsden M, Stronks K, Gemke RJ, et al. Psychosocial stress during pregnancy is related to adverse birth outcomes: results from a large multi-ethnic community-based birth cohort. Eur J Environ Public Health. 2012;23(3):485-91.

7. Nasreen HE, Kabir ZN, Forsell Y, Edhborg M. Low birth weight in offspring of women with depressive and anxiety symptoms during pregnancy: results from a population based study in Bangladesh. BMC Public Health. 2010;10(1):515.

8. Sanchez SE, Puente GC, Atencio G, Qiu C, Yanez D, Gelaye B, et al. Risk of spontaneous preterm birth in relation to maternal depressive, anxiety and stress symptoms. J Reprod Med. 2013;58:25.

9. Lewis SJ, Relton C, Zammit S, Smith GD. Approaches for strengthening causal inference regarding prenatal risk factors for childhood behavioural and psychiatric disorders. J Child Psychol Psychiatry. 2013;54:1095-108. https://doi.org/10.1111/jcpp.12127.

10. Smith GD. Assessing intrauterine influences on offspring health outcomes: can epidemiological studies yield robust findings? Basic Clin Pharmacol Toxicol. 2008;102(2):245-56

11. D'onofrio BM, Lahey BB, Turkheimer E, Lichtenstein P. Critical need for family-based, quasi-experimental designs in integrating genetic and social science research. Am J Public Health. 2013;103(S1):S46-55.

12. Magnus P, Birke C, Vejrup K, Haugan A, Alsaker E, Daltveit AK, et al. Cohort Profile Update: The Norwegian Mother and Child Cohort Study (MoBa). Int J Epidemiol. 2016;45(2):382-8. https://doi.org/10.1093/ije/dyw02.

13. Tambs K, Røysamb E. Selection of questions to short-form versions of original psychometric instruments in MoBa. Nor Epidemiologi [Norsk Epidemiologi]. 2014;24:195-201.

14. Wadhwa PD, Sandman CA, Porto M, Dunkel-Schetter C, Garite TJ. The association between prenatal stress and infant birth weight and gestational age at birth: A prospective investigation. Am J Obstet Gynecol. 1993;169(4):858-65.

15. Staneva A, Bogossian F, Pritchard M, Wittkowski A. The effects of maternal depression, anxiety and precieved stress during pregnancy on preterm birth: A systematic review. Women Birth. 2015;28:179-93.
16. Weaver ICG, et al. Stress and the emerging roles of chromatin remodeling in signal intergration and stable transmission of reversible phenotypes. Frontiers in Behav Neurosci. 2017;11:41. https://doi.org/10.3389/fnbeh. 2017.00041.

17. Coussons-Read ME, Lobel M, Carey JC, Kreither MO, D'Anna K, Argys L, et al. The occurrence of preterm delivery is linked to pregnancy-specific distress and elevated inflammatory markers across gestation. Brain, Behav Immun. 2012;26(4):650-9. https://doi.org/10.1016/j.bbi.2012.02.009.

18. Dunkel Schetter C, Tanner L. Anxiety, depression and stress in pregnancy: implications for mothers, children, research, and practice. Curr Opin Psychiatry. 2012;25(2):141-8. https://doi.org/10.1097/YCO.0b013e3283 503680.

19. Wadhwa PD, Entringer S, Buss C, Lu MC. The contribution of maternal stress to preterm birth: issues and considerations. Clin Perinatol. 2011;38(3):351-84. https://doi.org/10.1016/j.clp.2011.06.007.

20. Cohen S, Miller GE, Rabin BS. Psychological stress and antibody response to immunization: a critical review of the human literature. Psychosom Med. 2001;63(1):7-18. https://doi.org/10.1097/00006842-20010 1000-00002.

21. Madianos PN, Lieff S, Murtha AP, et al. Maternal periodontitis and prematurity. Part II: Maternal infection and fetal exposure. Ann Periodontol. 2001;6(1):175-82. https://doi.org/10.1902/annals.2001.6.1.175.

22. Lahey BB, D'Onofrio BM. All in the Family: Comparing Siblings to Test Causal Hypotheses Regarding Environmental Influences on Behavior. Curr Dir Psychol Sci. 2010;19(5):319-23. https://doi.org/10.1177/09637 21410383977.

23. Kendler KS. Causal Inference in Psychiatric Epidemiology. JAMA Psychiatry. 2017;74(6):561-2. https://doi.org/10.1001/jamapsychiatry.2017.0502

24. Sjölander A. A cautionary note on the use of attributable fractions in cohort studies. Stat Methods Med Res. 2016;25(6):2434-43. https://doi. org/10.1177/0962280214523953.

25. Frisell T, Oberg S, Kuja-Halkola R, Sjolander A. Sibling comparison designs: bias from non-shared confounders and measurement error. Epidemiol. 2012;23(5):713-20. https://doi.org/10.1097/EDE.0b013e31825fa230.

\section{Publisher's Note}

Springer Nature remains neutral with regard to jurisdictional claims in published maps and institutional affiliations.

Ready to submit your research? Choose BMC and benefit from

- fast, convenient online submission

- thorough peer review by experienced researchers in your field

- rapid publication on acceptance

- support for research data, including large and complex data types

- gold Open Access which fosters wider collaboration and increased citations

- maximum visibility for your research: over 100M website views per year

At BMC, research is always in progress.

Learn more biomedcentral.com/submissions 